\title{
New guidelines for diagnosis and treatment of insomnia
}

\author{
Luciano Ribeiro Pinto Jr. ', Rosana Cardoso Alves², Eliazor Caixeta ${ }^{3}$, \\ John Araujo Fontenelle ${ }^{4}$, Andrea Bacellar ${ }^{5}$, Dalva Poyares ${ }^{1}$, \\ Flavio Aloe², Geraldo Rizzo ${ }^{6}$, Gisele Minhoto ${ }^{7}$, Lia Rita Bittencourt ${ }^{1}$, \\ Luiz Ataide Jr. , Márcia Assis9 , Márcia Pradella-Hallinan?', \\ Maria Christina Ribeiro Pinto ${ }^{1}$, Raimundo Nonato D. Rodrigues ${ }^{10}$, \\ Rosa Hasan², Ronaldo Fonseca ${ }^{11}$, Stella Tavares ${ }^{1}$
}

\begin{abstract}
The Brazilian Sleep Association brought together specialists in sleep medicine, in order to develop new guidelines on the diagnosis and treatment of insomnias. The following subjects were discussed: concepts, clinical and psychosocial evaluations, recommendations for polysomnography, pharmacological treatment, behavioral and cognitive therapy, comorbidities and insomnia in children. Four levels of evidence were envisaged: standard, recommended, optional and not recommended. For diagnosing of insomnia, psychosocial and polysomnographic investigation were recommended. For non-pharmacological treatment, cognitive behavioral treatment was considered to be standard, while for pharmacological treatment, zolpidem was indicated as the standard drug because of its hypnotic profile, while zopiclone, trazodone and doxepin were recommended.

Key words: insomnia, diagnosis of insomnia, treatment of insomnia, cognitive behavioral therapy.
\end{abstract}

\section{Novas diretrizes no diagnóstico e tratamento das insônias}

\section{RESUMO}

A Associação Brasileira de Sono reuniu especialistas em medicina do sono com o objetivo de desenvolver novas diretrizes no diagnóstico e tratamento das insônias. Nós consideramos quatro níveis de evidência: padrão, recomendado, opcional e não recomendado. Os tópicos abordados foram: conceito, avaliação clínica e psicossocial, indicação da polissonografia, tratamento farmacológico, terapia comportamental cognitiva, comorbidades e insônia na infância. Para o diagnóstico da insônia, foi recomendada uma avaliação psicossocial e a realização da polissonografia, enquanto que no que se refere ao tratamento, foi estabelecido como padrão a indicação da terapia comportamental cognitiva, e, quanto ao tratamento farmacológico, foi indicado o uso do zolpidem como hipnótico padrão, e sendo recomendado o zopiclone, a trazodona e a doxepina.

Palavras-chave: insônia, diagnóstico da insônia, tratamento da insônia, terapia comportamental cognitiva.

Even today, insomnia remains a clinical entity that is difficult to diagnose and complex to treat, demanding an approach with appropriate strategy and planning. Insomnia, as a symptom, syndrome or disease, has serious social and professional conse- quences, affecting daily activities and rendering individuals incapable of performing their tasks. It therefore generates a high cost for society.

In November 2008, the Brazilian Sleep Society brought together doctors who 
specialize in sleep medicine, in São Paulo. The meeting aimed to provide new guidelines for diagnosing and treating insomnia. During this meeting, the following subjects were considered: concepts, clinical and psychosocial evaluations, recommendations for polysomnography, pharmacological treatment, behavioral and cognitive therapy, comorbidities and insomnia in children.

\section{METHOD}

Based on searches in the literature for articles, reviews and meta-analyses, five levels of evidence were put forward as recommendations for managing insomnia:

Level I - Randomized trials with low false-positive (alpha) and low false-negative (beta) errors (high power); evidence obtained from meta-analyses on randomized controlled trials; Level II - Randomized trials with high falsepositive (alpha) and (or) high false-negative (beta) errors (low power); evidence obtained from at least one randomized controlled trial; Level III - Nonrandomized concurrent cohort comparisons between patients with and without receiving a concomitant nutritional intervention; evidence obtained from at least one well-designed, controlled study, without randomization; Level IV - Nonrandomized historical cohort comparisons between current patients who received a nutritional intervention, and former patients (from the same institution or from the literature) who did not; Level V - Case series without controls; evidence obtained from expert committee reports or opinions and/or clinical experiences from respected authorities. Based on these five levels of evidence, the recommendations for interventions were considered to be: standard (levels I and II); recommended (levels III and IV), optional (level V) and not recommended, when no level of evidence existed ${ }^{1,2}$.

\section{Concept (standard)}

Insomnia is defined as a disorder that is characterized by difficulty in falling asleep or maintaining sleep. Furthermore, insomnia is also related to dissatisfaction with the quality of sleep, thus resulting in daily physical and emotional symptoms that have an impact on social and cognitive performance ${ }^{3}$.

\section{Classification (standard)}

According to the latest classification of sleep disorders (2005), insomnia is divided into the following forms: acute insomnia, psychophysiological insomnia, paradoxical insomnia, idiopathic insomnia, insomnia associated with mental disorders, insomnia associated with systemic diseases and insomnia associated with inadequate habits ${ }^{4-6}$.

Acute insomnia, transitory insomnia or adjustment insomnia

The essential element for this diagnosis is the pres- ence of symptoms of acute insomnia caused by a triggering causal factor that is clearly identified in an individual who previously had a normal sleeping pattern, without insomnia complaints. This clinical condition lasts no longer than one month ${ }^{4}$.

\section{Primary chronic insomnia}

In the etiopathogenesis of primary insomnia, three points should be considered: predisposing (genetic and constitutional), precipitating and perpetuating factors. Predisposing factors depend on hyperactivity of the awakening system (stress response mechanisms), hyperactivity of the hypothalamic-pituitary-adrenal axis, anxiety and depression, abnormalities in the mechanisms of sleep-wakefulness homeostasis, abnormalities in the circadian rhythm (circadian sleep-wakefulness control) and abnormalities of the intrinsic mechanisms of sleep-wakefulness control ${ }^{7-11}$. The precipitating and perpetuating factors depend on psychosocial factors, behavioral changes and cognitive characteristics.

Primary insomnia can be divided in three subtypes, namely psychophysiological, idiopathic and paradoxi$\mathrm{cal}^{4}$. Psychophysiological insomnia occurs concomitantly with a cognitive hyperalert state that is characterized by anxiety related to the act of sleeping and the presence of neurocognitive symptoms such as fatigue and irritability. Idiopathic insomnia starts before puberty and persists throughout adulthood, and a family history of insomnia is often present. In paradoxical insomnia, subjective complaints of poor quality sleep can be observed, despite the lack of objective sleep abnormalities on polysomnography. This subtype of insomnia is related to sleep misperception.

\section{Associated insomnia}

[1] Mental disorder - The essential factor of this type of insomnia is the temporal and causal relationship with an underlying mental disorder. Mood disorders such as depression, dysthymia, cyclothymia, bipolar disorder, anxiety, schizophrenia and somatoform disorders are examples of mental disorders associated with this type of insomnia ${ }^{3-5,12-18}$.

[2] Inadequate sleep hygiene - This is related to habits that are inappropriate for good quality of sleep, for example psychologically stressful activities, consumption of caffeine, nicotine, alcohol and heavy meals, vigorous physical activity close to bed time, inconstant time for going to sleeping and waking up, long naps or naps near the main time for sleeping ${ }^{4}$.

[3] Medical condition - This sleep disorder is related to particular medical conditions, for example painful syndromes, infections, metabolic diseases, hyperthyroidism and neurological diseases ${ }^{4}$.

[4] Use of substances or medication - This sleep disorder is related to the use of a drug or substance such as al- 
cohol, stimulants (amphetamine and derivatives) or antidepressives ${ }^{4}$.

\section{Comorbidities}

\section{Obstructive sleep apnea}

In 1973, Guilleminault et al described the association between insomnia and obstructive sleep apnea, and called it "sleep-insomnia apnea syndrome"19. The relationship between these two common sleep disorders is complex and unclear. There is a higher incidence of breathing disorders in insomniac patients than there is in the general population ${ }^{20,21}$. The severity of insomnia symptoms is strongly correlated with the severity of apnea, thereby characterizing comorbidity. Lichstein et al demonstrated that high proportions of individuals, particularly the elderly, present this combined condition of undiagnosed sleep apnea and insomnia ${ }^{22}$. Therefore, polysomnography (PSG) can help identify a substantial number of breathing disorders that are associated with insomnia ${ }^{23,24}$.

Women at the premenopausal and menopausal periods are more likely to develop sleep complaints and disorders than are women of a fertile age. Conjugated hormonal therapy (estrogen and progesterone) has been shown to efficiently improve general sleep complaints, as well as insomnia and $\mathrm{OSAS}^{25}$. Benzodiazepine drugs are associated with reductions in wakefulness, reductions in the muscle tonus of airways and decreases in the ventilatory response to hypoxemia. Therefore, these drugs are considered to be inappropriate for treating these comorbidities. The use of CPAP or oral devices also interferes negatively in the quality of sleep, particularly during the adaptation phases.

\section{Fibromyalgia}

Patients with fibromyalgia present persistent tiredness and physical fatigue, associated with non-restoring sleep and diffuse muscle pain. Usually, these patients have the perception of a sleep disorder associated with fatigue. Pharmacological treatment mainly consists of tricycles antidepressants and cyclobenzaprine ${ }^{26-32}$.

\section{Circadian rhythm disorders}

The delayed sleep phase syndrome is a circadian rhythm disorder, characterized by delays in falling asleep and in waking in the morning. This condition usually starts during childhood and adolescence, and is seldom misinterpreted as insomnia, particularly idiopathic insomnia ${ }^{33-42}$.

\section{Restless legs syndrome and periodic movements of limbs}

The restless legs syndrome is characterized by sensory disorders that mainly affect the lower limbs, particularly before falling sleep, thus leading to difficulty in falling asleep. Periodic movements of limbs usually accompany the restless legs syndrome during sleep, leading to a fragmented sleeping pattern, which affects the quality of sleep. Periodic movements of the lower limbs can occur during sleep, independently of the existence of restless legs syndrome. In these cases, the repercussions on the sleep profile, with insomnia or daytime hypersomnolence, must be analyzed one by one, in each case ${ }^{43}$.

\section{Evaluation}

When considering the etiopathogenesis of insomnia, it is important to highlight that insomnia may be of biological, environmental, behavioral or psychological nature. Likewise, the factors causing and perpetuating insomnia are interrelated with social, professional and family factors. Therefore, insomnia evaluations need to be broad-based, covering the patients' medical, psychological and social characteristics.

\section{Medical evaluation (standard)}

Evaluations on insomniac patients should begin by taking a rigorous and detailed medical history in which the history of symptoms is recorded, including the start of insomnia and its progression to a chronic condition, along with treatments already used and repercussions of the abnormal sleeping pattern during the day, such as somnolence, tiredness, fatigue and reduction of attention, concentration and memory ${ }^{44}$.

Nighttime habits that should be recorded include: bedtime, activities in bed, turning off lights, time to fall asleep, time to waking up in the morning, time to getting up, sleep quality, number of awakenings, time spent awake during the night and reports of snoring and leg movements.

Day habits that should be recorded include: mealtimes, work and study periods, daytime naps, physical activity, smoking habit, alcohol intake, use of drugs and medications.

Bedroom conditions that should be recorded include: condition of the bed, mattress and pillows, number of people who sleep in the same bed, luminosity, noise, temperature and presence of a TV, computer or audio equipment in the bedroom.

\section{Psychosocial evaluation (recommended)}

This has the aim of investigating, in greater detail, the main precipitating and perpetuating factors of insomnia. A psychosocial evaluation must be carried out, taking into account the systemic focus, i.e. the insomnia symptoms are analyzed within the context of patients lives, and what these symptoms allow or cover ${ }^{45-48}$.

\section{Subsidiary examinations (recommended)}

It is recommended that every insomniac patient should undergo complementary examinations when there is a suspicion of any systemic disease.

Questionnaires (recommended)

The use of a sleep diary, as well as other questionnaires, is fundamental to cognitive-behavioral therapy. 


\section{Polysomnography (recommended)}

In order to investigate comorbidities such as obstructive sleep apnea, and for objective evaluation of sleep in cases of diagnosing inadequate perception, polysomnography is recommended as an auxiliary method for diagnosing of insomnia, whenever possible ${ }^{49-52}$.

\section{Treatment of primary insomnia}

\section{Cognitive-behavioral therapy (standard)}

Today, cognitive-behavioral therapy (CBT) is a standard treatment for primary insomnia. It must not be used alone but, rather, in association with pharmacological therapy ${ }^{53-58}$. CBT presents an advantage over pharmacological treatment: the low risk of side effects and the long-term maintenance of sleep pattern improvement. CBT has a limited and defined period of use, from four to eight sessions. It is a focal and direct type of therapy, in which patients play an active role and are co-responsible for their treatment. It can be undertaken individually or in groups ${ }^{59-62}$.

The interventions are educational, behavioral and cognitive, and their theoretical basis is the behavioral model of insomnia proposed by Spielman. According to this model, three main factors can cause insomnia: predisposing, precipitating and perpetuating factors. The main $\mathrm{CBT}$ targets are the precipitating and perpetuating factors. The main behavioral and cognitive techniques are sleep hygiene, stimulus-control therapy, therapy of bedtime and sleeping time restriction, relaxation techniques, cognitive restructuring, paradoxical intention and cognitive therapy in sleep misperception disorders ${ }^{63-67}$.

[1] Sleep hygiene: This is a psychoeducational intervention containing basic information on sleep habits and hygiene. It includes instructions for establishing regular sleeping times; going to bed only when feeling sleepy and not using the bed as a means of trying to sleep; not spending the day worrying about sleeping time; having control over time; avoiding the use of stimulants (coffee, cigarettes, drugs, black tea, Coca-Cola and chocolate); avoiding alcohol consumption before sleeping; and avoiding high liquid consumption before sleeping. It includes suggestions for dinner (light foods) not less than two hours before going to sleep, and for regular physical activity, preferably in the mornings. It evaluates the bedroom conditions: comfort, temperature, noise, and stresses the importance of having a bedroom that is silent, aired, clean and organized.

[2] Stimulus-control therapy: This aims towards educating insomniac patients on how to establish a more appropriate sleep-wakefulness rhythm and limit the time awake and the behavior allowed in the bedroom/bed. The main instructions for patients include the following items: to go to bed only when feeling sleepy; avoid any behav- ior other than sleep or sex in the bedroom/bed; if feeling incapable of sleeping, the patient should get up from bed and go to another place to do some relaxing activity in an environment with little light, and only go back to bed when feeling somnolence again; to keep to a fixed time for waking up, seven days per week, independently of the amount of sleep obtained; not to nap or to lie down during the day, to remove the TV, stereo and computer from the bedroom; not to eat, read, work, watch TV or use a computer in the bedroom/bed.

[3] Therapy of bedtime and sleeping time restriction: The aim of this therapy is to consolidate sleep through restricting the time that patients spend in bed to the average time they spend sleeping (i.e. the number of hours that they really spend sleeping), based on the information in the sleep diary. This technique creates a mild state of sleep deprivation that may cause daytime somnolence. However, at the same time, it provides sleep consolidation, thus making it easier to fall asleep, improving sleep efficiency and decreasing latency and variability between nights. It is not recommended to have less than four to five hours of sleep, and the necessary adjustments must be made in relation to time spent in bed, according to patients' responses to the proposed treatment. If patients reach $90 \%$ sleep efficiency, 15 minutes are added to the time allowed in bed and, if the efficiency is less than $85 \%$, 15 minutes are taken away.

[4] Relaxation techniques: The aim of teaching relaxation techniques is to show patients how tense and hypervigilant they are during both day and night. Progressive relaxation is the treatment for insomnia that has been studied most. Patients are guided to tension and relax the major muscle groups sequentially, while observing the sensation of tension and relaxation.

[5] Cognitive restructuring: This is mainly based on cognitive symptoms that can cause or perpetuate insomnia. Cognitive restructuring works on concerns, thoughts, false attitudes, irrational beliefs about sleep and amplification of its consequences, false ideas about the causes of insomnia and disbelief about sleep induction practices and about their own capacity to sleep. The idea is to make patients abandon the symptoms of insomnia, by reminding them that the way in which events are thought about or judged determines the way that individuals feel about them.

[6] Paradoxical intention: This technique reduces the anticipatory anxiety associated with the fear of trying to fall sleep and not being capable of doing so, since insomniacs usually believe that they have lost their natural capacity to fall asleep. Patients are instructed to go to bed and stay awake and try not to sleep; this makes them more relaxed and not under obligation to fall asleep. They consequently fall asleep faster. 
[7] Cognitive therapy for sleep misperception disorders: This therapy works on the relationship between patients' subjective perceptions of total sleeping time and the total sleeping time obtained through PSG. The intention of this approach is to give patients objective data on sleep efficiency obtained through PSG and make them comprehend that they are sleeping for longer than they think. This technique also makes them more relaxed regarding the quantity of sleep they consider necessary, and it enables them to fall asleep more easily when this new reality is acquired ${ }^{51-52}$.

\section{Pharmacological treatment}

Pharmacological treatment consists of the use of hypnotic drugs that induce sleep, mainly because they act on the main inhibitory system of the central nervous system, the GABA system. Additionally, substances presenting sedative effects, such as antidepressants, may be used. More recently, medications that act on melatoninergic receptors have been considered promising as drugs for treating insomnia ${ }^{68-72}$.

\section{GABA-A receptor-selective agonist hypnotics}

[1] Zolpidem (standard): This is the hypnotic drug used for treating insomnia. Zolpidem is an imidazopyridine that was developed in 1980 and has been used since 1990. It was the first selective $\alpha 1$ agonist. It is rapidly absorbed (in approximately one hour) and presents a short half-life of 2.5 hours. Its bioavailability ranges from $65 \%$ to $70 \%$. Plasma concentration peaks occur 1.5 hours after drug intake. The therapeutic doses range from 5 to $10 \mathrm{mg}$, and the drug is metabolized in the liver and eliminated by the kidneys. In older people, and in cases of liver or kidney failure, the recommended dose is $5 \mathrm{mg}^{73}$. Although the use of sleep inductors for treating chronic insomnia is only recommended for one month, clinic trials have suggested that zolpidem remains effective and safe for a prolonged period of use, i.e. more than 35 days, in a $10 \mathrm{mg} \operatorname{doses}^{74,75}$. The use of zolpidem reduces the cyclic alternating pattern types A1 and A2, even when in intermittent use ${ }^{76,77}$.

Slow-release zolpidem (zolpidem MR, still not available in Brazil) is a new formulation used for patients with difficulty in maintaining their sleep. This formulation comprises pills with immediate release and pills for prolonged release, which maintains plasma concentrations for three to six hours after intake ${ }^{78,79}$. Zolpidem can also be used intermittently over the long term, in accordance with patient needs, without rebound insomnia appearing ${ }^{80-82}$.

[2] Zopiclone (recommended): This is a hypnotic drug that is recommended for treating insomnia. Zopiclone is a cyclopyrrolone that differs from zolpidem because of its longer half-life (5.3 hours) and its action on receptors containing the subunits $\alpha 1$ and $\alpha 2$. The recommended dose is 3.7 to $7.5 \mathrm{mg}$. A few side effects after withdrawal have been described; however, the residual effects on the following day may be attributed to its long half-life ${ }^{83}$.

[3] Zaleplon (recommended) - not available: This is a pyrazolopyrimidine that links to the $\alpha 1$ receptor, thus making the drug a hypnotic agent that can be recommended for treating insomnia. The recommended dose is $10 \mathrm{mg}$ and its half-life is approximately one hour. Because of these characteristics, zaleplon is indicated for sleep induction, while showing little effect on sleep maintenance. Zaleplon has already been in the Brazilian market, but it was withdrawn, which limits its use in this country ${ }^{84}$.

[4] Eszopiclone (recommended) - not available: This is a zopiclone isomer of cyclopyrrolone that is recommended for treating insomnia. Eszopiclone is rapidly absorbed and presents a relatively long half-life. The dose must be individualized, but ranges from 1 to $3 \mathrm{mg}$ before going to bed ${ }^{85-87}$.

[5] Indiplon (recommended) - not available: This is a pyrazolopyrimidine with similarities to zolpidem, zopiclone and zaleplon that is selective for receptors that contain a subunit $\alpha 1$. It is a hypnotic drug recommended for treating insomnia. This drug has a formulation for immediate release (indiplon IR), which is indicated for initial insomnia, and a controlled formulation (indiplon MR), which lasts six to eight hours and is indicated for patients with complaints regarding sleep maintenance. The recommended dose ranges from 15 to $30 \mathrm{mg}$, taken just before going to bed $^{88}$.

\section{Antidepressants}

Sedative antidepressants (tricyclic, trazodone, doxepin and mirtazapine) are alternatives for pharmacological treatment of insomnia. However, there are no doubleblind randomized studies proving the efficacy and safety of these agents. Some tricyclic antidepressants such as amitriptyline improve sleep continuity and efficiency and produce sedation during the day ${ }^{89}$.

[1] Trazodone (recommended): Trazodone seems to be the second most commonly prescribed agent for treating insomnia. It belongs to the pharmacological group of serotonin reuptake inhibitors, and has antagonist action on the adrenergic receptors $\alpha$ 1, 5-HT1A and 5-HT2. Trazodone slightly suppresses REM sleep and improves sleep continuity. The recommended dose is $50 \mathrm{mg} / \mathrm{day}^{90}$.

[2] Doxepin (recommended): This is a tricyclic antidepressant with antagonist effect on histamine $\mathrm{H} 1 / \mathrm{H} 2$ receptors. It has been shown to be efficient if used in small doses (1 to $6 \mathrm{mg} / \mathrm{night}$ ), for treating insomnia. It does not cause clinically significant residual or anti-cholinergic effects ${ }^{91}$.

[3] Mirtazapine (optional): This is an atypical antidepressant. Its mechanism of action depends on the increased noradrenergic activity provided by the antagonist effect of the drug on alpha-2a adrenergic receptors, and nonspecific blockage of serotonergic reuptake. Mir- 
tazapine is a postsynaptic antagonist (blocker) of $5 \mathrm{TH}_{2 \mathrm{~A}}$ and $5 \mathrm{TH}_{2} \mathrm{C}$ and $5-\mathrm{HT}_{3}$ with sedative and anxiolytic effects. Its histaminic $\mathrm{H} 1$ anti-receptor activity explains the strong sedative effect, and this is the antidepressant with the greatest sedative effect among the currently available drugs. The recommended doses range from 7 to $30 \mathrm{mg}^{92}$.

[4] Amitriptyline (optional): This presents significant sedative effects due to its anticholinergic, anti-histaminic and anti-alpha ${ }_{1}$ profile, and also due to the blockage of $5 \mathrm{HT}_{2 \mathrm{~A}}$ and $5 \mathrm{HT}_{2 \mathrm{C}}$ receptors. The sedative effects are immediate, preceding the antidepressant effects, and decrease after a few weeks of treatment. The recommended dose ranges from 12.5 to $50 \mathrm{mg}$.

[5] Mianserin (optional): This is an atypical antidepressant with sedative effect that occurs through antihistaminic 1 and $5 \mathrm{HT}_{2 \mathrm{~A} / 2 \mathrm{C}}$ receptor antagonistic effects. There are no long-term studies proving the efficacy and safety of mianserin for treating insomnia.

\section{Valerian (optional)}

Valerian (valepotriates) may be an option for treating insomnias and is used as an auxiliary medication when discontinuing benzodiazepine among chronic users. Some studies have reported that its mechanism of action is related to GABA. Valerian may act during sleep through other mechanisms, through MT1 and MT2 receptors (melatonin) and through the A1 adenosinergic receptor and some subtypes of 5-HT receptors ${ }^{93}$.

\section{Benzodiazepines (optional)}

Benzodiazepines (BZDs) link nonspecifically to the alpha-1 and alpha- 2 subunits of the GABA-A postsynaptic receptor and to any subunit of the gamma type. BZDs increase the affinity of the GABA-A postsynaptic receptor with endogenous GABA, and increase the intensity and duration of the inhibitory effects through boosting chloride channels. The link to the subunit alpha- 1 is responsible for the hypnotic and cognitive effects of this drug, while the link to the subunit alpha- 2 is responsible for the anxiolytic, anti-convulsion and muscle-relaxing effects. Withdrawal of BZDs may bring back the insomnia or cause rebound insomnia in patients, with worse symptoms than those presented before treatment. The presence of anxiety and the intensity of insomnia depend on patients' psychological profiles. Gradual and slow discontinuation of BZDs, with technical support, is recommended. The abstinence symptoms when discontinuing BZDs depend on a variety of factors. Many chronic users will be able to discontinue treatment successfully, provided that it is done with an appropriate technique ${ }^{94-95}$.

Medication abuse often occurs among chronic users. Tolerance reflecting the progressive increase of BZD doses also depends on several factors. However, there are patients who do not develop tolerance after using BZDs for a long time. There are studies demonstrating the existence of a correlation between prolonged use of BZDs and increased risk of death. Amplification of obstructive ventilatory disorders during sleep, sedation, suppression of selfcare, falls, confusion, amnesia and other possible drugrelated symptoms may explain the increased mortality. BZDs are not indicated for individuals with drug addiction and alcohol abuse. Special care is necessary with elderly individuals, patients with kidney, liver and lung dysfunctions, and patients with psychiatric problems. BZDs may worsen the ventilatory disorders during sleep and are not indicated during pregnancy, or for individuals whose work may require prompt waking up and quick decisionmaking.

Among BZDs, clonazepam (optional), midazolam (optional) and estazolam (optional) can be used. The other BZDs are not recommended.

\section{Melatonin receptor agonists (optional)}

[1] Ramelteon: This is a new hypnotic drug that has been approved for treating chronic insomnia. It is an agonist with high selectivity for melatonin MT1 and MT2 receptors ${ }^{96}$. The $8 \mathrm{mg}$ recommended dose is rapidly absorbed (0.75-0.94 hour) and presents a half-life of 1.3 hours. Due to its short half-life, Ramelteon is indicated for treating initial insomnia ${ }^{97-99}$. It is not efficient in maintaining sleep. Ramelteon is safe with regard to cognitive effects on the following day, and has not been shown to cause rebound insomnia when discontinued after chronic use. It has not shown any potential for abusive use or dependence $\mathrm{e}^{100-102}$.

[2] Agomelatine: This is an antidepressant with agonist action on melatonin receptors 1 and 2 , and antagonist effect on serotoninergic 5-HT2C receptors. Because of its melatoninergic agonist effect, agomelatine may be a potential regulator of the circadian rhythm of depressed patients, thus leading to an added contribution for improving depression. Use of this medication at a dose of 25 to $50 \mathrm{mg}$ has been shown to improve sleep quality, with reduced sleep latency, reduced awakening and increased slow-wave sleep ${ }^{103,104}$.

\section{Other pharmacological and new perspectives}

Antihistamines are optional, while antipsychotics are not recommended.

New GABA agonists, like tiagabine and gaboxadol, are still not available in Brazil and are not recommended. These drugs are inhibitors of GABA reuptake, and are among the new perspectives for treating insomnia ${ }^{105-110}$.

\section{Insomnia during childhood Classification (standard)}

Insomnia during childhood is divided into behavioral insomnia, psychophysiological insomnia, insomnia in special populations, insomnia associated with clinical conditions and insomnia associated with the use of 
medications. The most common clinical causes of insomnia during childhood are pain or cramps, recurrent otitis, reflux, medications (stimulants or corticoids), night asthma attacks and airway obstructions. ${ }^{111}$ The main type of insomnia in children is behavioral insomnia, but this is an exclusion diagnosis. During the first approach towards the child, the clinical causes of insomnia must always be eliminated.

[1] Behavioral insomnia during childhood: This occurs in 10 to $30 \%$ of preschool children. The International Classification of Sleep Disorders (ICSD-2005) defines children's difficulty in falling asleep and/or maintaining sleep as the essential characteristic of behavioral insomnia. These problems are associated with certain attitudes among children or their parents, and they can be classified into two types: association disorder and lack-of-limit disorder ${ }^{112}$.

[2] Association disorder: There are certain conditions associated with the start of sleep that are necessary for children to fall asleep and for them to go back to bed after each awakening during the night. Positive associations are conditions that children can provide for themselves (pacifiers/dummies or teddy bears), while negative associations need assistance from someone else (baby bottles or rocking). The negative associations also include external stimuli (television or toys) or different situations (parents' bed or a car ride). When the condition associated with sleep is present, the child falls asleep rapidly. If the condition associated with sleep is not present, the child presents frequent and long-duration nighttime awakenings.

The diagnostic criteria consist of findings that falling asleep is a slow process that requires special conditions, and that associations with falling asleep are problematic and require much effort. When association elements are absent, the start of sleep is significantly delayed or sleep is fragmented. Nighttime awakening requires intervention so that these children can fall asleep again.

[3] Lack-of-limit disorder: This is presented as a refusal or delay in going to bed at the established time. On the other hand, delaying the time for going to sleep might include several requests (feeling thirsty, needing the bathroom or asking for one more goodnight kiss) or additional activities (watching TV or reading one more story). Once these children fall asleep, their sleep quality is normal and they tend to have few awakenings. However, children with lack-of-limit disorder normally have a shorter sleeping time (30 to 60 minutes).

The diagnostic criteria consist of difficulty in falling asleep or maintaining sleep; postponing or refusing to go to bed at the appropriate time or refusing to go back to bed after nighttime awakening; inability of the parents to establish appropriate sleep behavior for the child; lack of explanation for the sleep disorder in terms of other sleep disorders, clinical conditions, mental or neurological diseases, or use of medications.

[4] Insomnia associated with neurological and psychiatric conditions: Most syndromes with central nervous system dysfunction present some kind of sleep abnormality in their clinical presentation.

\section{Diagnosis}

Medical evaluation (standard) - The main questions in evaluating sleep disorders in pediatric cases include duration of sleep, sleep routines, events associated with sleep, daily behavior, humor and cognitive function. It is also essential to find out about significant events in the child's life, such as parents' divorce, changes of school or moving house, or events involving siblings. A sleep diary must be kept over a one or two-week period, and this is always useful for finding out about sleeping patterns and for following them over time. Parents are asked to write details about what time the child went to bed, how long the child took to fall asleep, the frequency and duration of nighttime awakening, the time and duration of daily naps, the time of waking up in the morning and the total duration of sleep ${ }^{113}$.

Polysomnography (optional): Polysomnographic testing and actigraphy are optional in diagnosing and treating insomnia in children. They are indicated only when necessary.

\section{Consequences}

Children with insufficient duration of sleep present fatigue and irritability. Parents may present negative feelings towards their children and, in order to avoid frustrations during sleeping times, they may postpone the sleep routine, which delays the start of sleep even more and prolongs the cycle of addiction.

\section{Treatment}

[1] Behavioral approach (standard): Time for going to sleep: The appropriate time for a child to go to sleep, from infancy to preschool age, should be between 7:00 and $8: 30 \mathrm{pm}$. When bedtime is later than this, children get very tired, irritated and have difficulty in sleeping. The time for going to sleep should not vary between weekdays and weekends. Daytime naps are essential for the child. The need for daytime naps tends to disappear between the ages of three and six years ${ }^{114}$.

Bedtime routine: Establishing a routine is very important for children's lives. The bedtime routine can be started at three months of age, through establishing a constant time for going to sleep. Any electronic equipment near the child must be turned off before starting the ritual for going to sleep.

Falling asleep independently: Children with insomnia are incapable of falling asleep without their parents' intervention, such as rocking or feeding. Children must be put in the cradle or go to bed when they are sleepy, but still awake, and then they must fall asleep independently. 
There are several methods that help children fall asleep by themselves, for example, "extinction" alone, gradual "extinction", positive routines, brief visits and weaning children from their parents' presence ${ }^{115}$.

"Extinction" alone consists of leaving the child cry until falling sleep. "Extinction" is based in the theory that behavior that is reinforced increases in frequency, while behavior that is ignored will disappear with time. If parents are regular and do not attend their child's calls, in general, the child will be able to sleep alone after three to five nights. Gradual extinction is an alternative for parents who do not want to use extinction alone. This method consists of putting the sleepy, but awake, child in the cradle and then ignoring the calls or crying for gradually increasing periods. When observing the child at night, the visit must be short and uniform, without lights and without speaking loudly or touching the child.

The gradual reduction of the mother's presence includes an initial phase in which physical contact is reduced at bedtime. Mothers who feed their children at bedtime must do this activity earlier in another room and only rock the child to sleep. After achieved success with this strategy, the child must be put in the cradle and the mother must caress the child's head or arm until the child falls asleep. In the second step, the mother's presence in the bedroom must be reduced. The third step consists of increasing the time between each visit. Positive routines aim to create a pleasant and positive environment not only for the child but also for the parents.

[2] Pharmacological treatment (optional): Pharmacological treatment must be considered as the last option. Most medications prescribed for insomnia among adults are not recommended for children. However, in specific cases, generally when there is an underlying neurological or psychiatric disease, BDZs can be used (clonazepam, clobazam, midazolam or diazepam), as well as zolpidem, zopiclone, chloral hydrate, levomepromazine, promethazine, carbamazepine, clonidine, risperidone and melatonin, always considering the age of the child and the risk/benefit associated with the use of these drugs ${ }^{116}$.

\section{REFERENCES}

1. US Department of Health and Human Services. Definitions of types of evidence and grading of recommendations according to the US Agency for Health Care Policy and Research Rockville, MD: Agency for Health Care Policy and Research, 1993:107. (AHCPR publication No 92-0023)

2. Sackett DL. How are we to determine whether dietary interventions do more good than harm to hypertensive patients? Can J Physiol Pharmacol 1986;64:781-783.

3. Diagnostic and statistical manual of mental disorders. Text revision, $4^{\text {th }}$ Ed. Washington, DC: American Psychiatric Association, 2000.

4. International Classification of Sleep Disorders. American Academy of Sleep Medicine. Second edition. Diagnostic and coding manual. Westchester, IL: American Academy of Sleep Medicine, 2005.

5. NIH State of the Science Conference Statement: manifestations and management of chronic insomnia in adults. June 13-15, 2005. J Clin Sleep Med 2005:1:412-422
6. Summers M, Cristostomo M, Stepanski E. Recent contemporary reviews in sleep medicine: developments in the classification, evaluation and treatment of insomnia. Chest 2006;130:276-286.

7. Borbely AA. A two process model of sleep regulation. Hum Neurobiol 1982;1:195-204.

8. Espie CA. Understanding insomnia through cognitive modelling. Sleep Med Rev 2007;8(Supp 4):S3-S8.

9. Richardson GS. Human physiological models of insomnia. Sleep Med Rev 2007:8(Suppl 4):S9-S14.

10. Roth T, Roehrs T, Pies R. Insomnia: pathophysiology and implications for treatment. Sleep Med Rev 2007;11:71-79.

11. Vgontzas AN, Bixler BO, Lin HM, et al. Chronic insomnia is associated with nyctohemeral activation of the hypothalamic-pituitary-adrenal axis: clinical implications. J Clin Endocrinol Metab 2001;86:3787-3794.

12. Buysse DJ, Angst J, Gamma A, Ajdacic V, Eich D, Rössler W. Prevalence, course, and comorbidity of insomnia and depression in young adults. Sleep 2008;31:473-480.

13. Chang PP, Ford DE, Mead LA, Cooper-Patrick L, Klag MJ. Insomnia in young men and subsequent depression: the Johns Hopkins Precursors Study. Am J Epidemiol 1997;146:105-14.

14. Edinger JD, Bonnet MH, Bootzin RR, et al. Derivation of research diagnostic criteria for insomnia: report of an American Academy of Sleep Medicine work group. Sleep 2004; 27:1567-96.

15. Gregory AM, Caspi A, Eley TC, Moffitt TE, Oconnor TG, Poulton R. Prospective longitudinal associations between persistent sleep problems in childhood and anxiety and depression disorders in adulthood. J Abnorm Child Psychol 2005;33:157-163.

16. Neckelmann D, Mykletun A, Dahl AA. Chronic insomnia as a risk factor for developing anxiety and depression. Sleep 2007;30:873-880.

17. Ohayon MM, Roth T. Place of chronic insomnia in the course of depressive and anxiety disorders. J Psychiatr Res 2003;37:9-15.

18. Riemann D, Voderholzer U. Primary insomnia: a risk factor to develop depression? J Affect Disord 2003;76:255-259.

19. Guilleminault C, Edridge F, Dement W. Insomnia whit sleep apnea: a new syndrome. Science 1973;181:856-858

20. Krakou B, Melendres D, Ferreira E, et al. Prevalence of insomnia symptoms in patients with sleep-disordered breathing. Chest 2001;120:1923-1929.

21. Vgontzas AN, Kales A, Bixler EO, Manfredi RL, Vela-Bueno A. Usefulness of polysomnographic studies in the differential diagnosis of insomnia. Int J Neurosci 1995;82:47-60.

22. Lichstein K, Reidel B, Lester K, Aguillard R. Occult sleep apnea in a recruited sample of older adults with insomnia. J Consult Clin Psychol 1999;67:405-410.

23. Avidan AY. Insomnia in the geriatric patient. Clin Cornestone 2003;5:51-60.

24. Miller EH. Women and insomnia. Clin Cornestone 2004;6(Suppl 1B):S8-S18.

25. Young T, Rabago D, Zgierska D, Austin D, Laurel F. Objective and subjective sleep quality in premenopausal, perimenopausal, and postmenopausal woman in the Wisconsin Sleep Cohort Study. Sleep 2003;26:667-672.

26. Aaron LA, Burke MM, Buchwald D. Overlapping conditions among patients with chronic fatigue syndrome, fibromyalgia, and temporomandibular disorder. Arch Intern Med 2000;160:2221-2227.

27. Chakrabarty S, Zoorob R. Fibromialgia. Am Fam Physician 2007;76:247-254

28. Drewes AM, Nielsen KD, Arendt-Nielsen L, Birket-Smith L, Hansen LM. The effect of cutaneous and sleep pain on the electroencephalogram during sleep: an experimental study. Sleep 1997;20:632-640.

29. Moldofsky H, Scarisbrick P, England R, Smythe H. Musculoskeletal symptoms and non-REM sleep disturbances in patients with "fibrositis syndrome" and healthy subjects. Psychosomat Med 1975;37:341-351.

30. Lineberger MD, Means MK, Edinger JK. Sleep disturbance in fibromyalgia. Sleep Med Clin 2007;2:31-39.

31. Yunus MB, Ahles TA, Aldag JC, Masi AT. Relationship of clinical features with psychological status in primary fibromyalgia. Arthritis Rheum 1991;34:15-21.

32. Wolf F. Smythe H A, Yunus MB, et al. American College of Rheumathology 1990 criteria for the classification of fibromyalgia. Report of the multicenter Criteria Committee. Arthritis Rheum 1990;33:160-172.

33. Ando K, Kripke DF, Ancoli-Israel S. Estimated prevalence of delayed and advanced sleep phase syndromes. Sleep Res 1995;24:509.

34. Pelayo R, Thorpy MJ, Govinski P. Prevalence of delayed sleep phase syndrome among adolescents. Sleep Res 1988;17:392.

35. Standards of Practice Committee of the American Academy of Sleep Medicine: practice parameters for the role of actigraphy in the study of sleep and circadian rhythms; an update for 2002. Sleep 2003;26:337-341.

36. Weitzman ED, Czeisler CA, Coleman RM. Delayed sleep phase syndrome: a 
chronobiological disorder with sleep-onset insomnia. Arch Gen Psychiatry 1981;38:737-746.

37. Cajochen C, Krauchi K, Wirz-Justice A. Role of melatonin in the regulation of human circadian rhythms and sleep. J Neuroendocrinol 2003;15:432-437.

38. Campbell SS, Dawson D, Anderson MW. Alleviation of sleep maintenance insomnia with timed exposure to bright light. J Am Geriatr Soc 1993;41:829-836.

39. Czeisler CA, Richardson GS, Coleman RM, et al. Chronotherapy: resetting the circadian clock of patients with delayed sleep phase insomnia. Sleep 1991; 4:1-21.

40. Morgenthaler TI, Lee-Chiong T, Alessi C, et al. Practice parameters for the clinical evaluation and treatment of circadian rhythm sleep disorders. Sleep 2007;30:1445-1459

41. Sack RL, Auckley D, Auger RR, et al. Circadian rhythm sleep disorders. Part I: basic principles, shift work and jet lag disorders. Sleep 2007;30:1460-1483.

42. Zisapel N. Circadian Rhythm Sleep Disorders: pathophysiology and potential approaches to management. CNS Drugs 2001;15:311-328.

43. Brazilian Group of Study on the Restless Legs Syndrome. Restless legs syndrome. Diagnosis and treatment: opinion of Brazilian experts. Arq Neuropsiquiatr 2007;65:721-727.

44. Shuttle-Rodin S, Broch L, Buisse D, Dorsey C, Sateia M. Clinical guideline for the evaluation and management of chronic insomnia in adults. J Clin Sleep Med 2008:4:487-504

45. Martikainen K, Partinen M, Hasan J, Laippala P, Urponen H, Vuori I. The impact of somatic health problems on insomnia in middle age. Sleep Med 2003:4:201-206.

46. Kappler C, Honagen F. Psychosocial aspects of insomnia: results of a study in general practice. Eur Arch Psychiatry Clin Neurosci 2003;253:49-52.

47. Leger D. Sleep and quality of life in insomnia. In: Verster FC, Pandi-Pesussal, Steiner DL (Eds). Sleep and quality of life in clinical medicine. Totowa, NJ: Human Press, 2008:47-51.

48. Leger D, Guilleminault C, Bader G, Levy E, Paillard M. Medical and socio-professional impact of insomnia. Sleep 2002;25:625-629.

49. Clete A, Kushida C, Littner MR, et al. Practice parameters for the indications for polysomnography and related procedures: an update for 2005. Sleep 2005;28:499-521.

50. Littner M, Hirshkowitz M, Kramer M, et al. American Academy of Sleep Medicine; Standards of Practice Committee Practice parameters for using polysomnography to evaluate insomnia: an update. Sleep 2003;26:754-60.

51. Pinto Jr. LR. Insônia. In: Tufik S (Ed). Medicina e biologia do sono. São Paulo: Manole, 2008:206-217.

52. Pinto Jr. LR, Pinto MCR, Goulart LI, et al. Sleep perception in insomniac, sleep breathing disordered and healthy volunteers: an important sleep parameter. Sleep Med Rev 2009;10:865:868

53. American Academy of Sleep Medicine Review. Nonpharmacological treatment of chronic insomnia. Sleep 1999;22:1134-1156.

54. Chesson Jr AL, Anderson MD, Littner M, et al. Pratical parameters for the nonpharmacological treatment of chronic insomnia. Sleep 1999;22:1128-1133.

55. Edinger JD, Wohlgemuth WK, Radtke RA, Marsh GR, Quillian R. Cognitive behavioral therapy for treatment of chronic primary insomnia: a randomized controlled trial. Jama 2001;285:1856-1864.

56. Morin CM, Culbert JP, Schwartz SM. Nonpharmacological interventions for insomnia: a meta-analysis of treatment efficacy. Am J Psychiatry 1994;151:1172-1180.

57. Morin C. Psychological and pharmacological approaches to treating insomnia: critical issues in assessing their separate and combined effects. Clin Psychology Ver 1996;16:521-542.

58. Morin CM, Bootzin RR, Buysse DJ, Edinger JD, Espie CA, Lichstein KL. Psychological and behavioral treatment of insomnia: update of the recent evidence (1998-2004). Sleep 2006;29:398-414

59. Bastien $\mathrm{CH}$, Morin CM, Ouellet MC, Blais FC, Bouchard S. Cognitive behavioral therapy for insomnia: comparison of individual therapy, group therapy, and telephone consultations. J Consulting Clin Psychol 2004;72:653-659.

60. Loring MJ, Fraboni E. The use of cognitive therapy in groups. Internat J Partial Hospitalization 1990;6:173-179.

61. Backhaus J, Hohagen F, Voderholzer U, Riemann D. Long-term effectiveness of a short-term cognitive-behavioral group treatment for primary insomnia. Eur Arch Psychiatry Clin Neurosci 2001;251:35-41.

62. Spielman AJ, Nunes J, Glovinsky PB. Insomnia. In: Aldrich MS (Eds). Neurologic clinics. Sleep disorders. Vol 14(3). Philadelphia: W.B. Saunders, 1996:513-543.

63. Morin C. Insomnia: psychological assessment and management. New York: Guilford Press, 1993.

64. Espie CA. Practical management of insomnia: behavioral and cognitive techniques. British Med J 1993;306:509-512.
65. Morin CM, Hauri P, Espie CA. Spielman AJ, Buysse DJ, Bootzin RR. Nonpharmacological treatment of chronic insomnia. Sleep 1999:22:1134-1145.

66. Perlis ML, Jungquist C, Smith MT, Posner D. Cognitive behavioral treatment of insomnia: a session-by session quide. Springer Science, New York, 2005.

67. Morgenthaler TM, Kramer M, Alessi C, et al. Practice parameters for the psychological and behavioral treatment of insomnia: an update. An American Academy of Sleep Medicine report. Sleep 2006;29:1415-1419.

68. Ebert B, Wafford KA, Deacon S. Treating insomnia: current and investigational pharmacological approaches. Pharmacol Therap 2006;112:612-629.

69. HIH State-of-the-Science Conference Statement on Manifestations and Management of Chronic Insomnia in Adults. National Institutes of Health 2005, 22:1-30.

70. Morin CM. Measuring outcomes in randomized clinical trials of insomnia treatments. Sleep Med Rev 2003;7:263-279.

71. Lancel M. Role of GABA-a receptors in the regulation of sleep: initial sleep responses to peripherally administered modulators and agonists. Sleep 1999; 22:33-42.

72. Nutt D. Gaba-a receptors, subtypes, regional distribution, and function. J Clin Sleep Med 2006;2(Suppl):S7-S9.

73. Drover DR. Comparative pharmacokinetics and pharmacodynamics of shortacting hypnosedatives: zaleplon, zolpidem and zopiclone. Clin Pharmacokinet 2004:43:227-238.

74. Perlis ML, MacCall WV, Krystal AD, Walsh JK. Long-term, non-nightly administration of zolpidem in the treatment of patients with primary insomnia. L Clin Psychiatry 2004;65:1128-1137.

75. Scharf MB, Roth T, Vogel GW, Walsh JK. A multicenter placebo-controled study evaluating zolpidem in the treatment of chronic insomnia. J Clin Psychiatry 1994;55:192-199

76. Parrino L, Smerieri A, Giglia F, Milioli G, De Paolis F, Terzano MG. Polysomnographic study of intermittent zolpidem treatment in primary sleep maintenance insomnia. Clin Neuropharmacology 2008;31:40-50.

77. Uchimura N, Nakajima T, Hayash K, et al. Effect of zolpidem on sleep architecture and its next-morning residual effect in insomniac patients: a randomized crossover comparative study with brotizolam. Prog Nueropsychopharmacol Biol Psychiatry 2006;30:22-29.

78. Hindmarch I, Stanley N, Legangeneux E, Embego S. Zolpidem modified-release significantly reduces latency to persistent sleep 4 and 5 hours post dose with standard zolpidem in a model assessing the return to sleep following nocturnal awakening. Sleep 2001;28:245-246.

79. Roerhs T, Soubrane C, Roth T. Zolpidem modified-release objectivity and subjectively improves sleep maintenance and retains the characteristics of standard zolpidem on sleep initiation and duration in elderly patients with primary insomnia. Sleep 2005;28:A244.

80. Cluydts R, Peeters K, De Bouyalsky I, Lavoisy J. Comparison of continuous versus intermittent administration of zolpidem in chronic insomniacs: a doublebind, randomized pilot study. J Inter Med Res 1998;26:13-24.

81. Hajak G, Cluydts R, Allain $\mathrm{H}$, et al. The challenge of chronic insomnia: is nonnightly hypnotic treatment a feasible alternative? Eur Psychiatry 2003;18: 201-219.

82. Walsh JK, Roth T, Randazzo A, Erman M. Eight weeks of non-nightly use of zolpidem for primary insomnia. Sleep 2000;23:1087-1096.

83. Van der Kleijn E. Effects of zopiclone and temazepam on sleep, behaviour and mood during the day. Eur J Clin Pharmacol 1989;36:247-251.

84. Elie R, Ruther E, Farr I, Emilien G, Salinas E. Sleep latency is shortened during 4 weeks of treatment with zaleplon, a novel nonbenzodiazepine hypnotic. Zaleplon clinic study group. J Clin Psychiatry 1999;60:536-544.

85. Fava M, McCall WV, Krystal A, et al. Eszopliclone co-administered with fluoxetine in patients with insomnia coexisting with major depressive disorder. Biol Psychiatry 2006;59:1052-1086.

86. Roth T, Walsh JK, Krystal A, Wessel T, Rohers TA. An evaluation of the efficacy and safety of eszopiclone over 12 months in patients with chronic primary insomnia. Sleep Med Rev 2005;6:487-495.

87. Pollack M, Kinrys G, Krystal A, et al. Eszopiclone coadministered with escitalopran in patients with insomnia and comorbid generalized anxiety disorder. Arch Gen Psychiatry 2008:65:551-562

88. Neubauer DN. Indiplon: the development of a new hypnotic. Expert Opin Investig Drugs 2005;14:1269-1276.

89. Tardito D, Perez J, Tiraboschi E, Musazzi L, Racagni G, Popoli M. Signaling pathways regulating gene expression, neuroplasticity, and neurotrophic mechanisms in the action of antidepressants: a critical overview. Pharmacol Rev 2006;58:115-34

90. Kaynak H, Kaynak D, Gözükirmizi, Guilleminault C. The effects of trazodone 
on sleep in patients trated with stimulant antidepressants. Sleep Med Rev 2004:5:15-20.

91. Hajak G, Rodenbeck A, Voderholzer U, et al. Doxepin in the treatment of primary insomnia: a placebo-controlled, double-blind, polysomnographic study. J Clin Psychiatry 2001;62:453-463.

92. Kang RH, Wong ML, Choi MJ, et al. Association study of the serotonin trans porter promoter polymorphism and mirtazapine antidepressant response in major depressive disorder. Prog Psychopharmacol Biol Psychiatry 2007;31: 1317-1321.

93. Poyares DR, Guilleminault C, Ohayon MM, Tufik S. Can valerian improve the sleep of insomniacs after benzodiazepine withdrawal? Progr Neuropsychopharmacol Biol Psychiatry 2002;26:539-545.

94. Poyares DR, Tufik S. The consumption of hypnotic and alertness drugs in a population that complains of sleep disorders in São Paulo. J Sleep Res 1996; 5(Suppl 1):S183.

95. Roehrs T, Pedrosi B, Rosenthal L, Roth T. Hypnotic self administration and dose escalation. Psychopharmacology 1996;127:150-154.

96. Kato K, Hirais K, Nishiyama K. Neurochemical properties of ramelteon (TAK375), a selective MT1/MT2 receptor agonist. Neuropharmacology 2005; 48: 301-310.

97. Greenblatt DJ, Harmatz JS, Karim A. Age and gender effects on the pharmacokinetics and pharmacodynamics of ramelteon, a hypnotic agent acting melatonin receptor MT1 and MT2. J Clin Pharmacol 2007;47:485-496.

98. Karim A, Tolbert D, Cao C. Disposition kinetics and tolerance of scalating of ramelteon, a high-affinity MT1 and MT2 melatonin receptor agonist indicated for treatment of insomnia. J Clin Pharmacol 2006;46:140-148.

99. Roth T, Stubbs C, Walsh JK. Ramelteon (TAK-375), a selective MT1/MT2-receptor agonist, reduces latency to persistent sleep in a model of transient insomnia related to a novel sleep environment. Sleep 2005;28:300-301.

100. Erman M, Seiden D, Zammit G, Sainati S, Zhang J. An efficacy, safety, and dose-response study of ramelteon in patients with chronic primary insomnia. Sleep Med Rev 2006;7:17-24.

101. Hirai K, Kita M, Ohta H, et al. Ramelteon (TAK-375) accelerates reentrainment of circadian rhythm after a phase advance of the light-dark cycle in rats. J Biol Rhytms 2005;201:27-37.
102. Sateia MJ, Kirby-Long, Taylor J. Efficacy and clinical safety of ramelteon: An evidence-based review. Sleep Med Rev 2008;12:319-332.

103. Fuchs E, Simon M, Schmelting B. Pharmacology of a new antidepressant: benefit of the implication of the melatoninergic system. Int Clin Psychopharmacol 2006;21(Suppl 1)S17-S20.

104. Rouillon F. Efficacy and tolerance profile of agomelatine and practical use in depressed patients. Int Clin Psychopharmacol 2006;21(Suppl 1)S31-S35.

105. Deacon S, Staner L, Staner C, Legters A, Loft H, Lundhal J. Effect of short-term treatment with gaboxadol on sleep maintenance and initiation in patients with primary insomnia. Sleep 2007;30:281-287.

106. Fink-Jensen A, Suzdak PD, Swedberg MD. The gamma-aminobutyric acid (GABA) uptake inhibitor, tiagabine, increase extracellular brain levels of GABA in awake rats. Eur J Pharmacol 1992;220:197-201.

107. Lancel M. Rele of GAGA-a receptors in the regulation of sleep: initial sleep responses to peripherally administered modulators agonist. Sleep 1999;22:33-42.

108. Mathias S, Zihl J, Steiger A, Lancel M. Effect of repeated gaboxadol administration on night sleep and next-day performance in healthy elderly subjects. Neuropsychopharmacology 2005; 30:833-841.

109. Walsh JK, Randazzo AC, Frankowski S, Shannon K, Schweitzer PK, Roth T. Dose-response effects of tiagabine on the sleep of older adults. Sleep 2005; 28:673-676.

110. Walsh JK, Deacon S, Dijik D, Lundahl J. The selective extrasynaptic GABA-a agonist, gaboxadol, improves traditional hypnotic efficacy and slow wave activity in a model of transient insomnia. Sleep 2007;30:593-602.

111. Nunes ML, Cavalcante V. Clinical evaluation and treatment of insomnia in childhood. J Pediatria 2005;81:277-286.

112. Owens JA. Pediatric insomnia. Sleep Med Clin 2006;1:423-435.

113. Moore M, Meltzer LJ, Mindell JA. Bedtime problems and night wakings in children. Prim Care Clin Office Pract 2008;5:569-581.

114. Mindel JA, Kuhl B, Lewin DS, Meltzer LJ, Sadeh A. Behavioral bed problems and night waking in infants and young children. Sleep 2006;29:1263-1276.

115. Meltzer $\sqcup$, Mindell JA. Behavioral sleep disorders in children and adolescents. Sleep Med Clin 2008:3:269-279.

116. Idiazábal Alecha MA, Estivill Sancho E. Tratamiento del insomnio en niños: aspectos farmacológicos. An Pediatr 2003;59:239-245. 